\title{
Hemorragia alveolar por consumo de cocaína.
}

\section{Gustavo Eduardo Ortega Ramírez, Javier Enrique Fajardo, Laura Marcela Peñaloza Guerra, Kristhel Andrea Neira Triana.}

\section{INTRODUCCIÓN}

En el mundo, la cocaína ocupa el tercer puesto en consumo después del cannabis y la 3-4 metilendioximetanfetamina (MDMA). La cocaína, en forma de bazuco o crack, posee una toxicidad a través de múltiples vías (centrales y periféricas). Las complicaciones secundarias a la toxicidad dependen de la vía de administración, pueden ser locales o sistemicas y van desde la lesión en el sitio de administración hasta la aparición de complicaciones sistémicas. Las complicaciones pulmonares, entre la que se destaca el "pulmón de crack", un síndrome pulmonar raro, de presentación aguda, aparece posterior a la inhalación de cocaína, donde las manifestaciones clínicas son inespecíficas. Existen otras implicaciones pulmonares como, las exacerbaciones de el empeoramiento de enfermedad respiratorias preexistentes, el barotrauma (neumomediastino y neumotórax), edema pulmonar, neumonitis intersticial, hemorragia alveolar difusa, entre otras.

\section{OBEJETIVO}

Presentar un caso de pulmón del crack secundario a inhalación de crack - cocaina en donde se señalan aspectos de importancia clínica.

\section{MATERIAL Y MEDOTOS}

Realización de historia clínica, toma de fotografías y búsqueda de evidencia científica en la literatura mundial.

\section{RESULTADOS}

El pulmón de crack, es un síndrome pulmonar agudo, que se presenta después de la inhalación de crack-cocaína y se considera una complicación rara y potencialmente fatal. En nuestro paciente, las manifestaciones clínicas, paraclínicas, imagenológicas y la evidencia de hemosiderofagos en la citología del lavado bronco alveolar, fue importante para establecer el diagnostico del pulmón de crack.

\section{CONCLUSIONES}

El pulmón del crack es un síndrome potencialmente letal relacionado con el consumo de cocaína o sus derivados. La identificación de la exposición puede no se fácil, ya que algunos no proporcionan información confiable, ocasionando la instauración de tratamientos innecesarios. Finalmente, en los casos agudos, el manejo de soporte bajo vigilancia clínica termina siendo la intervención apropiada y con muy buenos resultados, tal y como se pudo corroborar en nuestra paciente.

Adjuntos:pulmon-crack-torax-2.pdfpulmon-crack-torax.pdfpulmon-de-crack-histologia.pdf 3 archivos adjuntos

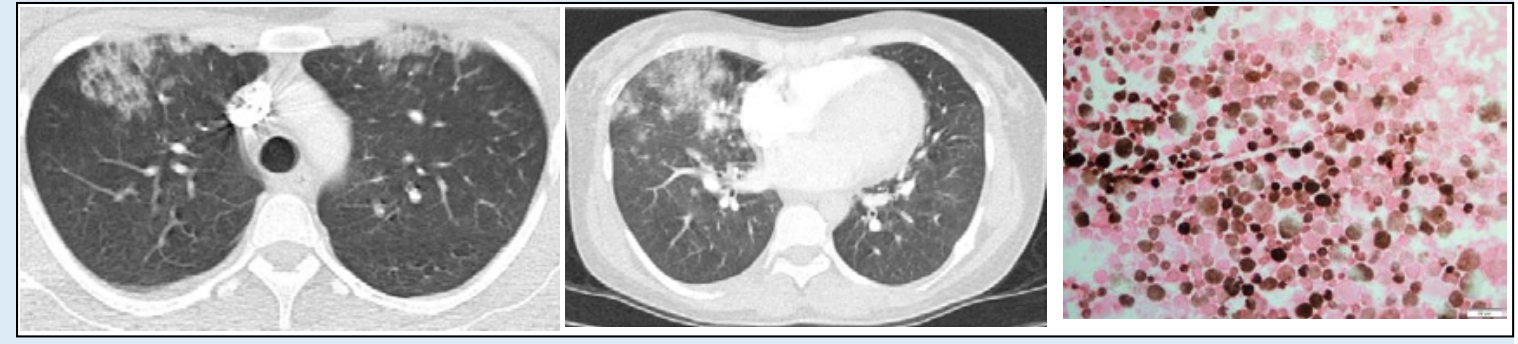

